Mini review

\title{
Electrochemistry in supercritical fluids: A mini review
}

\author{
Kathryn E. Toghill *, Manuel A. Méndez, Patrick Voyame \\ Laboratory of Physical and Analytical Electrochemistry, Ecole Polytechnique Federale de Lausanne, EPFL-ISIC-SB-LEPA, Station 6, Lausanne 1015, Switzerland
}

\section{A R T I C L E I N F O}

\section{Article history:}

Received 10 April 2014

Accepted 11 April 2014

Available online 24 April 2014

\section{Keywords:}

Supercritical fluids

Carbon dioxide

Hydrofluorocarbons

High pressure

Electrochemistry

\begin{abstract}
A B S T R A C T
A brief overview of the literature relating to electrochemical studies and processes undertaken in supercritical fluids is presented. This review mostly concerns carbon dioxide and hydrofluorocarbons, given the accessibility of their supercritical states, and does not consider the emerging body of research in expanded phase electrochemistry.
\end{abstract}

(c) 2014 Elsevier B.V. All rights reserved.

\section{Contents}

1. Introduction . . . . . . . . . . . . . . . . . . . . . . . . . . . . . . . . . . . . . . . . . . . . . . . . 27

2. Supercritical carbon dioxide $\left(\mathrm{scCO}_{2}\right)$. . . . . . . . . . . . . . . . . . . . . . . . . . . . . . . . . . . . . . . . . . . . 28

3. Hydrofluorocarbon supercritical fluids . . . . . . . . . . . . . . . . . . . . . . . . . . . . . . . . . . . . . . . . . . . . 29

4. Other supercritical fluids . . . . . . . . . . . . . . . . . . . . . . . . . . . . . . . . . . . . . . . . . . 29

5. Conclusions .. . . . . . . . . . . . . . . . . . . . . . . . . . . . . . . . . . . . . . . 29

Conflict of interest . . . . . . . . . . . . . . . . . . . . . . . . . . . . . . . . . 29

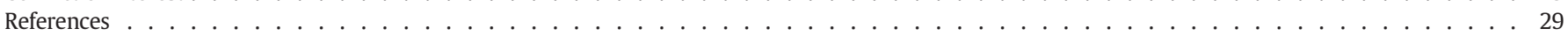

\section{Introduction}

Supercritical fluids (SCFs) are obtained when a compound surpasses its critical temperature $\left(\mathrm{T}_{\mathrm{C}}\right)$ and pressure $\left(\mathrm{P}_{\mathrm{C}}\right)$. At this point the fluid displays intermediate properties between a gas and a liquid, producing a unique medium with many of the advantages of both states of matter. Beyond the critical point the SCF density varies considerably with just small changes in the pressure or temperature. Due to this tunability and their unique physical properties, SCFs have featured heavily in a number of industrial processes, and more recently, gained interest in green chemistry processes in the replacement of organic solvents. The physical properties and industrial applications of SCFs have been extensively reviewed elsewhere $[1,2]$.

\footnotetext{
* Corresponding author.

E-mail address: kathryn.toghill@epfl.ch (K.E. Toghill).
}

As alternative solvents for electrochemical processes, SCFs remain an emerging field, despite 30 years of investigation. The predominant electrochemical application of SCFs to-date has been in electrodeposition, a subject comprehensively reviewed recently [3]. The electrochemistry of SCFs is overall a complex subject however, with complications arising from pressurised reactor designs, low dielectric constants and poor solubility of supporting electrolytes. Nonetheless highly desirable attributes for electrochemical systems such as the simple separation of reagents and products along with the vastly improved mass transport of dissolved species to the electrode surface can be found in SCFs, motivating research efforts. The supercritical properties of the most commonly used SCFs in electrochemistry are listed in Table $1 . \mathrm{CO}_{2}$ and hydrofluorocarbons are evidently far more accessible than $\mathrm{NH}_{3}$ and $\mathrm{H}_{2} \mathrm{O}$. The latter has clearly limited the use of $\mathrm{H}_{2} \mathrm{O}$ under supercritical conditions as it adds further complications in the electrochemical reactor design, whereas the low critical density of ammonia has limited its use. The following sections consider the main SCFs of electrochemical interest. 
Table 1

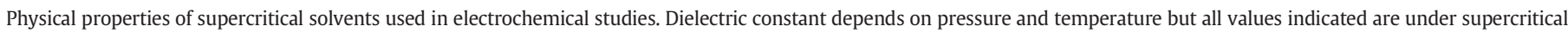
conditions.

\begin{tabular}{|c|c|c|c|c|c|}
\hline Solvent & Critical T (K) & Critical P (MPa) & Critical density $\left(\mathrm{g} / \mathrm{cm}^{-3}\right)$ & Dielectric constant $(\varepsilon)$ & Ref \\
\hline $\mathrm{CO}_{2}$ & 304.3 & 7.3 & 0.486 & $1.18-1.8$ & [3] \\
\hline $\mathrm{HCF}_{3}$ & 299.3 & 4.8 & 0.525 & $4.38-6.08$ & [35] \\
\hline $\mathrm{CF}_{3} \mathrm{CHF}_{2}$ & 339.33 & 3.6 & 0.571 & $3.09-9.72$ & [45] \\
\hline $\mathrm{CF}_{3} \mathrm{CH}_{2} \mathrm{~F}$ & 374.2 & 4.1 & 0.512 & $4.55-6.57$ & [45] \\
\hline $\mathrm{CH}_{2} \mathrm{~F}_{2}$ & 351.3 & 5.8 & 0.424 & $2.97-4.17$ & [45] \\
\hline $\mathrm{CHClF}_{2}$ & 369.3 & 5.0 & 0.522 & $2.31-3.11$ & [26] \\
\hline $\mathrm{NH}_{3}$ & 405.5 & 11.2 & 0.24 & $3.0-8.0$ & [46] \\
\hline $\mathrm{H}_{2} \mathrm{O}$ & 667 & 22.1 & 0.322 & $<5$ & [43] \\
\hline $\mathrm{SO}_{2}$ & 157.5 & 7.9 & 0.525 & Unavailable & [40] \\
\hline $\mathrm{CH}_{3} \mathrm{CN}$ & 547.7 & 4.8 & 0.237 & $4.5-18$ & [47] \\
\hline
\end{tabular}

\section{Supercritical carbon dioxide $\left(\mathrm{scCO}_{2}\right)$}

As a low cost, abundant and easy-to-handle SCF, with a readily attainable critical point, $\mathrm{CO}_{2}$ is often promoted as a green solvent [1,2]. For electrochemical studies however, it is not ideal, because of its low dielectric constant $(\varepsilon<1.8)$. The range of solutes is therefore limited, especially for ionic species, with even conventional organic solvent electrolytes proving insoluble in the supercritical phase [4,5]. Consequently $\mathrm{scCO}_{2}$ electrochemical research has predominantly focussed on overcoming low conductivity issues. The earliest report of $\mathrm{CO}_{2}$ as an electrochemical medium dates back to 1981 [6] for the electrodeposition of silver, though poor conductivity and ion-solvation properties limited interest in $\mathrm{scCO}_{2}$. Later publications focused on fundamental aspects of $\mathrm{scCO}_{2}$ with the aim to overcome the low solubility of ionic species. These approaches primarily concerned the implementation of microelectrode systems, the use of highly hydrophobic electrolytes, and the addition of polar co-solvents.

The first studies exclusively using $\mathrm{scCO}_{2}$ as solvent were in the late 1980s by Wightman et al. [7-9] Using water as a co-solvent and a microelectrode arrangement the group found that water aided the solvation of electrolyte $\left[{ }^{n} \mathrm{Hex}_{4} \mathrm{~N}\right]^{+}\left[\mathrm{PF}_{6}\right]^{-}$and allowed for a defined ferrocene $\left(\mathrm{Fc} / \mathrm{Fc}^{+}\right)$redox wave to be observed. Water was necessary to obtain an electrochemical signal with $0.64 \mathrm{M}$ without electrolyte giving rise to an uncharacteristic reverse peak [7]. This was postulated to be due to the deposition of insoluble $\mathrm{Fc}^{+}$salt on the electrode surface. Addition of electrolyte reduced the intensity of this reverse wave and conventional, reversible redox voltammetry for Fc was observed with $0.13 \mathrm{M}$ added water (Fig. 1a). Wightman and Michael later studied the direct modification of the microelectrode surface with a conductive ionic polymer membrane (Nafion), providing a conductive interface with which the dissolved Fc could interact [10]. Further developments lead to the appearance of surface modified electrodes that even allowed for studies of metallocenes without a polar co-solvent [11]. Water-in- $\mathrm{scCO}_{2}$ emulsions were also proven to raise the conductivity of the supercritical phase to obtain well defined voltammograms (Fig. 1b) [12], allowing their use in the electrochemical deposition of $\mathrm{ZnO}$ mesocrystals [13], electroplating of copper [14] and nickel [15], and electropolymerization of pyrrole in the presence of a surfactant [16]. The conductivity of the films obtained was comparable to films prepared in conventional solvents, but with a fine, homogeneous morphology unlike the uneven, nodular structure of the conventionally synthesised films.

In the 1990s Abbott et al. showed that very hydrophobic electrolytes, especially the class of the tetraalkylammonium tetraarylborate salts, could be dissolved in $\mathrm{scCO}_{2}$ to a limited extent without a polar modifier $[4,5]$. Voltammetry could be obtained, but analysis of data was difficult due to complications arising from strong adsorption processes [17]. The latter publication was also the first attempt to achieve macroscale voltammetry in this resistive medium. Abbott and Harper's comprehensive study highlighted the importance of solvent density on the solubility of the electrolyte with conductivity increasing from $10^{-8}$ to $10^{-7}$ $\mathrm{S} \mathrm{cm}^{-1}$ over the $313-343 \mathrm{~K}$ temperature range at $10 \mathrm{MPa}$. At $30 \mathrm{MPa}$ it was an order of magnitude higher. The authors attributed the better conductivity to improved solvation properties under conditions where greater fluid densities are obtained. Bulky, hydrophobic electrolytes
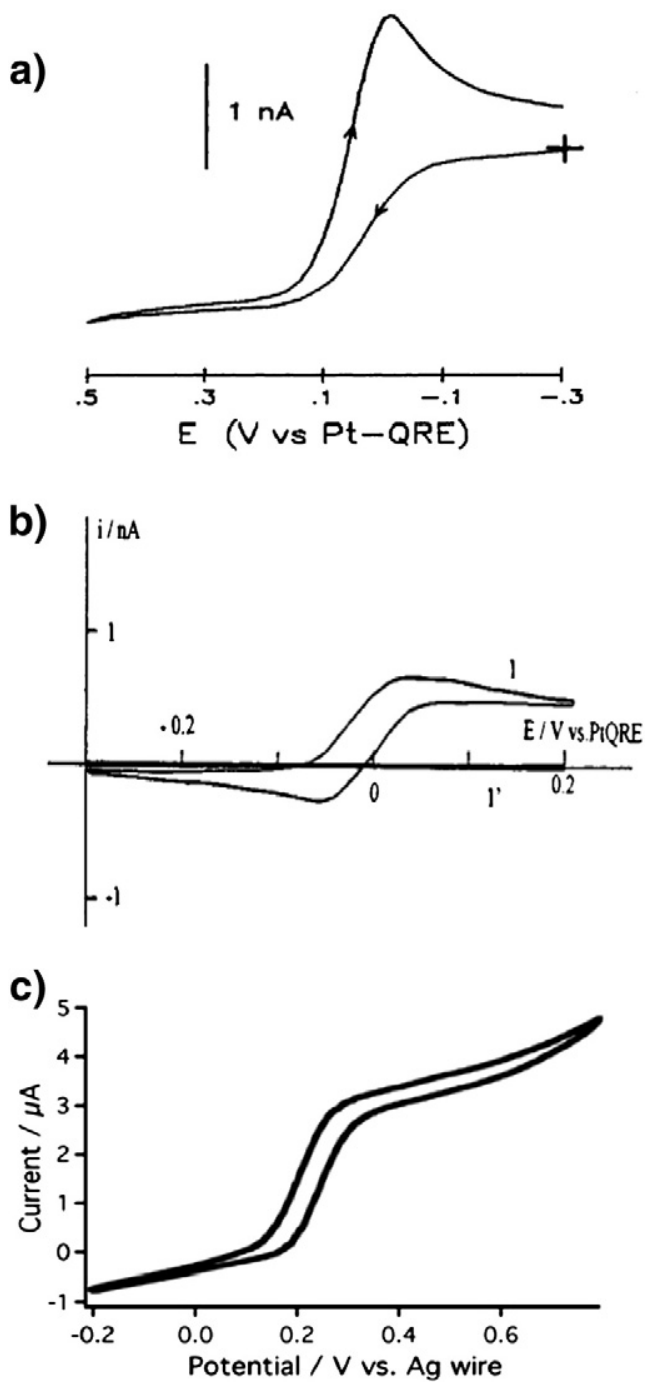

Fig. 1. a) $\mathrm{Fc}(200 \mu \mathrm{M})$ in $\mathrm{scCO}_{2}$ containing $0.13 \mathrm{M}$ water at $80{ }^{\circ} \mathrm{C}$ and $8.9 \mathrm{MPa}$. Scan rate of $100 \mathrm{mV} \mathrm{s}^{-1}$ using a Nafion-coated Pt microelectrode $(50 \mu \mathrm{m})$. b) Fc $(2 \mathrm{mM})$ in water-in- $\mathrm{scCO}_{2}$ emulsion at $38{ }^{\circ} \mathrm{C}$ and $121.6 \mathrm{MPa}$. Pt microelectrode (50 $\left.\mu \mathrm{m}\right)$, scan rate of $200 \mathrm{mV} \mathrm{s}^{-1}$. c) DMFc $(500 \mu \mathrm{M})$ in $\mathrm{scCO}_{2} / \mathrm{CH}_{3} \mathrm{CN}(30 \mathrm{vol} . \%)$ at $40{ }^{\circ} \mathrm{C}$ and $10 \mathrm{MPa}$ with $10 \mathrm{mM}\left[{ }^{n} \mathrm{Dec}_{4} \mathrm{~N}\right]^{+}\left[\mathrm{B}\left(\mathrm{C}_{6} \mathrm{~F}_{5}\right)_{4}\right]^{-}$electrolyte, Au electrode $(1 \mathrm{~mm})$, scan rate of $25 \mathrm{mV} \mathrm{s}^{-1}$.

Figures (a) and (b) reprinted with permission from [9] and [12] Copyright 2014 American Chemical Society. Figure (c) reproduced from [21] with permission from the PCCP Owner Societies. 
have since been commonplace in $\mathrm{scCO}_{2}$ electrochemistry, with recent advances focusing on the halogenation of the ions. An extensive study by Bartlett et al. evaluated the conductivity of a series of electrolytes and determined that cation fluorination has little effect but for the anion it was crucial [18]. Specifically BARF anions, fluorinated derivatives of $\left[\mathrm{BAr}_{4}\right]^{-}$, were the most soluble and conductive in a mixed $\mathrm{scCO}_{2}$ /acetonitrile fluid [18].

An alternative strategy proposed to enhance the ionic conductivity of the $\mathrm{scCO}_{2}$ is to add a highly polar and miscible co-solvent. To-date methanol [18,19], dimethylformamide [20] or acetonitrile $[18,21]$ has been employed. Organic co-solvents form a single phase with $\mathrm{scCO}_{2}$ and considerably improve the solubility of ionic species. This mixed solvent phase has been largely documented in the field electrodeposition $[3,18$, 22], with Bartlett et al. recently reviving interest in SCFs as electroplating media. Their research efforts have demonstrated that the unique mass transport properties and lack of surface tension in supercritical media permit the formation of well-defined nano-structured electrodeposits [3]. Other electrochemically driven reactions of interest studied in this mixed solvent phase are electrocarboxylation of benzyl chloride [23] and conducting polymer synthesis [24,25].

Well-defined cyclic voltammograms of metallocenes show enhanced diffusion to the electrode due to the low viscosity of the medium. This was particularly noted in a recent publication by Toghill et al. [21] in which macroscale voltammetry of decamethylferrocene (DMFc) was undertaken in a $\mathrm{scCO}_{2}$ /acetonitrile medium. At moderately fast scan rates the DMFc voltammetric signal transitioned from macroscale peak shape to a steady state profile (Fig. 1c). Computer simulations and experimental data suggested that a $60 \mu \mathrm{m}$ thick layer of acetonitrile coated the electrode, which was supplemented by DMFc in the $\mathrm{scCO}_{2}$ when the diffusion layer exceeded the thin layer. The results were reminiscent of Wightman's, in which a film of water coated the microelectrode surface to impart improved conductivity $[7,8]$.

\section{Hydrofluorocarbon supercritical fluids}

Despite the relatively mild conditions necessary for producing pure $\mathrm{scCO}_{2}$ (vide supra), its low dielectric constant remains a significant obstacle for its use in electrochemistry. To overcome this issue, halogenated SCFs have been proposed as a viable alternative to $\mathrm{CO}_{2}$ (Table 1). Amongst the first examples reported, Olsen and Tallman initially described the voltammetry of $\mathrm{Fc}$ in $\mathrm{CHClF}_{2}$ under sub- and supercritical conditions [26]. The $\mathrm{Fc} / \mathrm{Fc}^{+}$redox couple was found to behave reversibly in this SCF at platinum microelectrodes with small concentrations of $\left[{ }^{n} \mathrm{Bu}_{4} \mathrm{~N}\right]^{+}\left[\mathrm{BF}_{4}\right]^{-}$as supporting electrolyte. Further conductivity measurements revealed an inverse relationship between the fluid density and ion-pairing processes. Thus, at low densities (near the critical point), ion-pair formation is favoured and leads to more pronounced ohmic distortion of the voltammetric signals due to increased medium resistance [27]. Similar behaviour is observed for $\mathrm{CHF}_{3}$ where high ion-pair formation, especially in the low-density region, affects the voltammetric measurements due to increased resistivity and restricted ion migration processes [28,29].

Other readily accessible supercritical solvents with higher dielectric constants, $\mathrm{CH}_{2} \mathrm{~F}_{2}$ and $\mathrm{CF}_{3} \mathrm{CH}_{2} \mathrm{~F}$, were later investigated by Abbott et al. [30] These solvents were demonstrated to be suitable electrochemical media, allowing the dissolution of $\left[{ }^{n} \mathrm{Bu}_{4} \mathrm{~N}\right]^{+}\left[\mathrm{ClO}_{4}\right]^{-}$as supporting electrolyte to concentrations up to $0.1 \mathrm{M}$. More importantly, an impressive anodic potential window of over $9 \mathrm{~V}$ was found for $\mathrm{CF}_{3} \mathrm{CH}_{2} \mathrm{~F}$, allowing for the oxidation of $\mathrm{Xe}$ and $\mathrm{Cs}^{+}$. Continued investigations on the effect of dissolved electrolytes on the viscosity of supercritical electrolyte solutions showed that ionic solvation leads to a significant restructuring of the solvent, causing an increase as high as 32-fold in the viscosity of $\mathrm{CH}_{2} \mathrm{~F}_{2}$ [31]. Conductivity data for $\mathrm{CH}_{2} \mathrm{~F}_{2}$ and $\mathrm{CF}_{3} \mathrm{CH}_{2} \mathrm{~F}$ has also shown the existence of a linear relationship between the logarithm of the inverse of the ion association constant and the inverse of the dielectric constant. More importantly, a linear relationship was observed between the logarithm of the association constant and the density of the SCF [32]. The influence of ion-pair formation was also tested by the electrochemical oxidation of various ferrocene derivatives. The results indicated that deviations from the Nernstian ideal behaviour can be explained by a decrease in the activity coefficient of the electroactive species at high pressures [33].

Based on these important findings, halogenated supercritical solvents have found applications mainly in electropolymerization and electrodeposition processes. Thus, Atobe et al. reported the use of supercritical $\mathrm{CHF}_{3}$ for the oxidative polymerization of pyrrole and thiophene [34], whilst Bartlett et al. have extended their electrodeposition studies to fluorinated supercritical media [3,35]. Furthermore, the utilisation of scHFCs as media for $\mathrm{CO}_{2}$ reduction has been considered with promising results from the unique fluid [36].

\section{Other supercritical fluids}

In a series of publications by Bard et al. in the 1980s [37-40] more polar and less accessible SCFs such as water, ammonia and acetonitrile (Table 1) were assessed as electrochemical media. Supercritical $\mathrm{NH}_{3}$, with its appreciable cathodic potential window [37,41], was the first SCF to be employed for the electrodeposition of silver [42]. This medium produced needle-like dendritic deposits, quite distinct from those formed in the dense liquid phase. An electrochemical study of quinoline and acridine ions to ascertain mechanistic data was also undertaken. The low density and viscosity of $\mathrm{scNH}_{3}$ impede its ability to solvate ionic species however, despite an appreciable dielectric constant.

Supercritical water solutions also undergo large changes in its physical properties with pressure-volume-temperature (PVT) variations due to the loss of hydrogen bonding in the supercritical state. As an electrochemical medium, $\mathrm{scH}_{2} \mathrm{O}$ has the highest $\mathrm{T}_{\mathrm{C}}$ and $\mathrm{P}_{\mathrm{C}}$ making it a very difficult medium to work with. It is also highly corrosive and readily oxidized and reduced. These difficulties were such that Bard et al. revisited this system in 1997, devising corrosion-resistant apparatus to obtain voltammetric data of hydroquinone and iodine [43].

Bard's group also explored supercritical acetonitrile as part of the SCF series [44]. Despite possessing a moderate $\mathrm{P}_{C}$ the high $\mathrm{T}_{\mathrm{C}}$ (Table 1) early attempts at studying $\mathrm{scCH}_{3} \mathrm{CN}$ were problematic. Nonetheless, Cabrera and Bard [44] studied several compounds in the medium, and found FC and DMFc to be particularly suited as redox probes. Further work relating to these alternative SCFs has not been undertaken since this comprehensive series.

\section{Conclusions}

Despite 30 years of research, electrochemistry in SCFs remains in its infancy. Whilst limitations in $\mathrm{scCO}_{2}$ have been overcome to some extent, using an organic co-solvent to improve conductivity and solvation of electrolytes remains necessary. The move towards HFCs is promising, as co-solvents are no longer necessary, and reaction conditions, most importantly the temperature, remain accessible. Complex ion-pairing in the scHFCs may impede progress however. The potential for using these SCFs as solvents for highly oxidative processes, particularly in $\mathrm{CO}_{2}$ utilisation research, is anticipated to gain momentum. Overall, it is a field of slow progress with a lot of potential.

\section{Conflict of interest}

The authors declare no conflict of interest.

\section{References}

[1] R. Marr, T. Gamse, Chem. Eng. Process. 39 (2000) 19-28.

[2] W. Leitner, P.G. Jessop (Eds.), Supercritical Solvents, P.T. Anastas (Ed.), Handbook of Green Chemistry, vol. 4, Wiley-VCH, Weinheim, 2009.

[3] P.N. Bartlett, D.A. Cook, M.W. George, A.L. Hector, J. Ke, W. Levason, G. Reid, D.C. Smith, W. Zhang, Phys. Chem. Chem. Phys. 16 (2014) 9202-9219. 
[4] A.P. Abbott, T.A. Claxton, J. Fawcett, J.C. Harper, J. Chem. Soc. Faraday Trans. 92 (1996) 1747-1749.

[5] A.P. Abbott, J.C. Harper, Phys. Chem. Chem. Phys. 1 (1999) 839-841

[6] G. Silvestri, S. Gambino, G. Filardo, C. Cuccia, E. Guarino, Angew. Chem. Int. Ed. 20 (1981) 101-102.

[7] M.E. Philips, M.R. Deakin, M.V. Novotny, R.M. Wightman, J. Phys. Chem. 91 (1987) 3934-3936.

[8] D. Niehaus, M. Philips, A. Michael, R.M. Wightman, J. Phys. Chem. 93 (1989) 6232-6236.

[9] A.C. Michael, R.M. Wightman, Anal. Chem. 61 (1989) 270-272.

[10] A.C. Michael, R.M. Wightman, Anal. Chem. 61 (1989) 2193-2200.

[11] E.F. Sullenberger, A.C. Michael, Anal. Chem. 65 (1993) 2304-2310.

[12] H. Ohde, F. Hunt, S. Kihara, C.M. Wai, Anal. Chem. 72 (2000) 4738-4741.

[13] W.H. Lin, T.F.M. Chang, Y.H. Lu, T. Sato, M. Sone, K.H. Wei, Y.J. Hsu, J. Phys. Chem. C 117 (2013) 25596-25603

[14] T.-F.M. Chang, T. Shimizu, C. Ishiyama, M. Sone, Thin Solid Films 529 (2013) 25-28.

[15] T.-F.M. Chang, M. Sone, Surf. Coat. Technol. 205 (2011) 3890-3899.

[16] M. Jikei, S. Saitoh, H. Yasuda, H. Itoh, M. Sone, M.-a. Kakimoto, H. Yoshida, Polymer 47 (2006) 1547-1554.

[17] A.P. Abbott, J.C. Harper, J. Chem. Soc. Faraday Trans. 92 (1996) 3895-3898.

[18] P.N. Bartlett, D.C. Cook, M.W. George, J. Ke, W. Levason, G. Reid, W. Su, W. Zhang, Phys. Chem. Chem. Phys. 12 (2010) 492-501.

[19] J. Jun, P.S. Fedkiw, J. Electroanal. Chem. 515 (2001) 113-122.

[20] S. Chanfreau, P. Cognet, S. Camy, J.S. Condoret, J. Electroanal. Chem. 604 (2007) $33-40$.

[21] K.E. Toghill, P. Voyame, D. Momotenko, A.J. Olaya, H.H. Girault, Phys. Chem. Chem. Phys. 15 (2013) 972-978.

[22] J. Ke, W. Su, S.M. Howdle, M.W. George, D. Cook, M. Perdjon-Abel, P.N. Bartlett, W. Zhang, F. Cheng, W. Levason, G. Reid, J. Hyde, J. Wilson, D.C. Smith, K. Mallik, P. Sazio, Proc. Natl. Acad. Sci. U. S. A. 106 (2009) 14768-14772.
[23] S. Chanfreau, P. Cognet, S. Camy, J.S. Condoret, J. Supercrit. Fluids 46 (2008) $156-162$.

[24] P.E. Anderson, R.N. Badlani, J. Mayer, P.A. Mabrouk, J. Am. Chem. Soc. 124 (2002) 10284-10285.

[25] H. Yan, T. Sato, D. Komago, A. Yamaguchi, K. Oyaizu, M. Yuasa, K. Otake, Langmuir 21 (2005) 12303-12308.

[26] S.A. Olsen, D.E. Tallman, Anal. Chem. 66 (1994) 503-509.

[27] S.A. Olsen, D.E. Tallman, Anal. Chem. 68 (1996) 2054-2061.

[28] D.L. Goldfarb, H.R. Corti, J. Phys. Chem. B 108 (2004) 3368-3375.

[29] D.L. Goldfarb, H.R. Corti, J. Phys. Chem. B 108 (2004) 3358-3367.

[30] A.P. Abbott, C.A. Eardley, J.C. Harper, E.G. Hope, J. Electroanal. Chem. 457 (1998) 1-4

[31] A.P. Abbott, E.G. Hope, D.J. Palmer, Anal. Chem. 77 (2005) 6702-6708.

[32] A.P. Abbott, C.A. Eardley, J. Phys. Chem. B 104 (2000) 9351-9355.

[33] A.P. Abbott, N.E. Durling, Phys. Chem. Chem. Phys. 3 (2001) 579-582.

[34] M. Atobe, H. Ohsuka, T. Fuchigami, Chem. Lett. 33 (2004) 618-619.

[35] P.N. Bartlett, D.C. Cook, M.W. George, J. Ke, W. Levason, G. Reid, W. Su, W. Zhang, Phys. Chem. Chem. Phys. 13 (2011) 190-198.

[36] A.P. Abbott, C.A. Eardley, J. Phys. Chem. B 104 (2000) 775-779.

[37] R.M. Crooks, F.R.F. Fan, A.J. Bard, J. Am. Chem. Soc. 106 (1984) 6851-6852.

[38] A.C. McDonald, F.R.F. Fan, A.J. Bard, J. Phys. Chem. 90 (1986) 196-202.

[39] R.M. Crooks, A.J. Bard, J. Electroanal. Chem. 243 (1988) 117-131.

[40] C.R. Cabrera, E. Garcia, A.J. Bard, J. Electroanal. Chem. 260 (1989) 457-460.

[41] R.M. Crooks, A.J. Bard, J. Electroanal. Chem. 240 (1988) 253-279.

[42] R.A. Williams, S. Naiditch, Phys. Chem. Liq. 2 (1970) 67-75.

[43] C.Y. Liu, S.R. Snyder, A.J. Bard, J. Phys. Chem. B 101 (1997) 1180-1185.

44] C.R. Cabrera, A.J. Bard, J. Electroanal. Chem. 273 (1989) 147-160.

[45] A.P. Abbott, C.A. Eardley, R. Tooth, J. Chem. Eng. Data 44 (1999) 112-115.

[46] R.M. Crooks, A.J. Bard, J. Phys. Chem. 91 (1987) 1274-1284.

[47] E.U. Franck, R. Deul, Faraday Discuss. 66 (1978) 191-198. 